\title{
Study of High-Temperature Mechanical Properties of Q235 Galvanized Sheet
}

\author{
Qi Wang ${ }^{1, a}$, Juntao Wang ${ }^{1, b}$ and Xintang Wang ${ }^{1, c}$ \\ ${ }^{1}$ Department of Civil Engineering, Ningbo University, Zhejiang, Ningbo 315211, China \\ awxt196322@126.com, bwangjuntao@nbu.edu.cn, cwangxintang@nbu.edu.cn
}

\begin{abstract}
Keywords: high temperature, mechanical property, Q235 thin-walled galvanized sheet
Abstract. On summary of the existing research work on high temperature mechanical property and stress-strain relations of the commonly used metallic materials in engineering, study of the mechanical property of Q235 thin-walled galvanized sheet with depth of $2 \mathrm{~mm}$ in elevated temperature was presented. A series of steady tensile tests and transient tensile tests of the material was put forward for different temperatures using high temperature furnace, and the mechanical property indexes such as elastic modulus, yielding strength, ultimate strength and elongation of the material for different temperature were obtained. The results obtained here can be used for fire-resistance computation and design of the structure constructed with the material.
\end{abstract}

\section{Introduction}

Comparing with the general steel plate, the galvanized sheet also differs with it on the mechanical properties besides the improvement in the corrosion resistance [1]. As for the steel structure building, anticorrosion and fireproofing are two of the most vital aspects of ensuring the safety of the structure. Because of the galvanized sheet's great corrosion resistance, the research on its fireproofing is much more significant. T. Ranawaka [2] has studied high-temperature mechanical properties of the G250 and G550 thin-walled galvanized sheet with thickness of $0.6 \mathrm{~mm}, 0.8 \mathrm{~mm}$ and $0.95 \mathrm{~mm}$, which obtains the decreasing coefficient of yield strength of the material under different stress levels. Chen[3]has studied steady-state and transient high-temperature mechanical property of the G550 galvanized thin sheet, and the expressions of yielding strength, elastic modulus and ultimate strength of the material were presented. Kankanamge [4]has studied high-temperature mechanical properties of the cold-formed thin-walled steel structures with two kinds of thickness and strength grade, which is commonly used in Australia. Huang [5] has made experiment of high-temperature mechanical properties of the thin plate materials of cold-formed molding square steel tube, whose results are compared with the present design method. Yan [6] has made the experiments of mechanical property and bearing capacity of the connection of cold-formed thin-walled steel structures. But the hot dip galvanized sheet made in China is not involved in all these researches, and the relationship of stresses and strains presented in these researches has a certain application conditions. Thus, based on a series of steady high-temperature property tests and transient high-temperature property tests of Q235 thin-walled galvanized sheet made in China, the high-temperature mechanical property indexes of the galvanized sheet with thickness of $2 \mathrm{~mm}$ were presented, which may be applied to the fire-resistance design of cold-formed thin-walled steel structures and improvement of relevant design specification.

\section{Experimental Scheme}

2.1 Materials and Equipment of the Experiment. The material involved in this high-temperature tensile experiment is Q235 hot-dipped galvanized sheet with thickness of $2 \mathrm{~mm}$. According to the shape required by high-temperature loading equipment, in term of 《Tensile test method of metal in high-temperature 》, 《Tensile test method of room-temperature metal》 and 《Test method of tensile creep and duration of metal $》$, the specifications and sizes of specimen are finally determined as illustrated in Figure 1. 


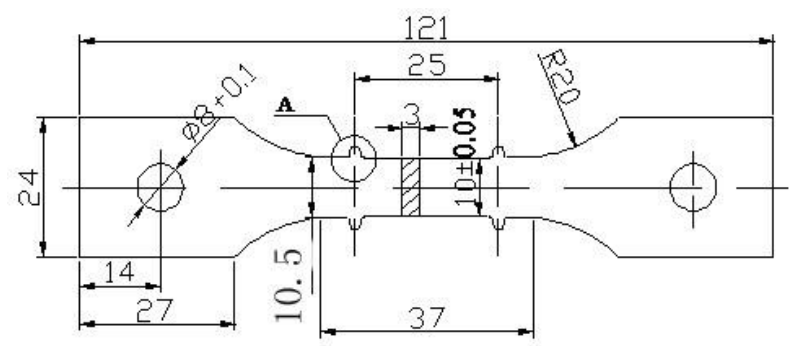

Fig.1 Dimension of specimens

The loading equipment used in the experiment is WAW-600C microcomputer-controlled electro-hydraulic servo universal testing machine. Its maximum testing force is $600 \mathrm{kN}$ and its precision of testing force is $\pm 1 \%$. The measurement and control software adopted in this testing machine is Super Test System 2011, that is the STS2011 software. Data was analyzed by the means of human-computer interaction and processed by the requirement of 《Tensile test method of metal material in room-temperature》(GB/T 228-2002). The heating and temperature-control equipment used in this experiment is GW-1200B high-temperature furnace produced in Changchun Fangrui Science Company Limited in China, voltage of which is three-phase $380 \mathrm{~V}$, power of which is $22 \mathrm{~kW}$, frequency of which is $50 \mathrm{~Hz}$, and it can be heated up to $1100^{\circ} \mathrm{C}$. The heating and temperature-control equipment consists of high-temperature furnace, GW-1200B controlling box, high-temperature rod, high-temperature collet, dial gauge and rotating arm. High-temperature furnace is equipped with a movable bracket so that it can be moved when there is a need for heating in the experiment. The loading heating equipment is illustrated in Figure 2.
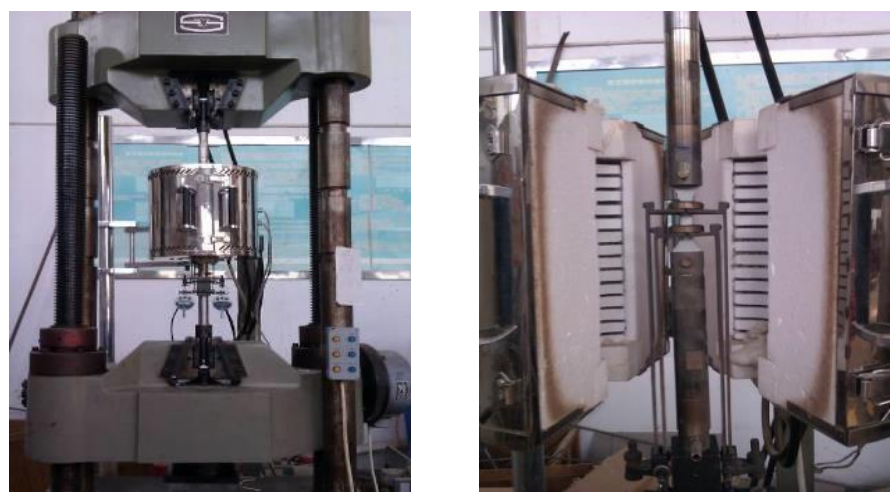

Fig.2 Loading-heating equipment

2.2 Testing Scheme. According to national standard 《Tensile test method of metal in high-temperature 》(HB5195-1996) and 《Tensile test method of room-temperature metal》 (HB5143-1996), the loading

condition of the specimens is: heating velocity is kept as $10 \sim 15^{\circ} \mathrm{C} / \mathrm{min}$; the target temperature muat be kept for 15 minutes before the tensile test for the constant temperature loading test; strain velocity should be about $0.005 / \mathrm{min}$ when the specimen is drawn. In order to obtain the exact test data, two sets of specimens are made, and steady tests together with transient tests are finished separately. The scheme and process of steady tests are shown as :

2.2.1 Steady Tests. The temperature level was divided into 12 temperature points, that is $20^{\circ} \mathrm{C} 、 150^{\circ} \mathrm{C} 、 200^{\circ} \mathrm{C} 、 250^{\circ} \mathrm{C} 、 300^{\circ} \mathrm{C} 、 350^{\circ} \mathrm{C} 、 400^{\circ} \mathrm{C} 、 450^{\circ} \mathrm{C} 、 500^{\circ} \mathrm{C} 、 550^{\circ} \mathrm{C} 、 600^{\circ} \mathrm{C}$ and $700^{\circ} \mathrm{C}$, totally. The process was (1) The data storage file was created in the deformation-temperature measurement software; (2)The upper end of high-temperature rod of the specimen was clamped with the upper collet of universal testing machine and the lower end of high-temperature rod was kept free; (3) The high-temperature furnace was adjusted to proper position to lay the specimen just in the middle of furnace; (4) The lower end of high-temperature rod was clamped and the gaps of high-temperature furnace was sealed up with fireproof asbestos; (5)The specimen was heated to required temperature of experiment 
and the force applied to the specimen was kept as $0.1 \mathrm{kN}$ in the meantime; (6) After the required temperature was reached, the temperature was kept constant for 15 minutes before two strain gauges were reset, then the load was applied to the specimen with strain rate of $0.005 / \mathrm{min}$ until the specimen come into failure.

2.2.2 Transient Tests. The temperature rise test was finished for constant load, and three stress levels were considered here, that is $0.7 f_{y}, 0.8 f_{y}$ and $0.9 f_{y} . f_{y}$ is the normal temperature yielding strength of the material. Two specimens are tested for each stress condition, and test of six specimens will be made. Valid data obtained in the test is the temperature value while the tensile specimen comes into failure. The way of installing specimen for the test is the same with the steady test mentioned above. After the specimen is fixed, the force applied to the specimen is added to the target value with rate of $0.1 \mathrm{kN} / \mathrm{s}$ and kept constant. Then the furnace was heated with velocity of $10 \sim 15^{\circ} \mathrm{C} / \mathrm{min}$ until the specimen is broken.

\section{Experimental Results and Analysis}

3.1 Test Phenomenon. For Q235 galvanized sheet, a set of specimens at every temperature point from $20^{\circ} \mathrm{C}$ to $800^{\circ} \mathrm{C}$ were respectively tested, and the main features are described as follows:

(1) At $150^{\circ} \mathrm{C}$ to $300^{\circ} \mathrm{C}$, the surface feature of specimen after cooling was mainly similar to that at normal temperature. The fractures were all silvery with metallic luster. There was necking phenomenon where the specimen was damaged.

(2) At $350^{\circ} \mathrm{C}$ to $450^{\circ} \mathrm{C}$, the surface feature of specimen after cooling was mostly not damaged and there was silvery luster on the surface. But above $400^{\circ} \mathrm{C}$, small area of zinc coat fallen off at both ends of the specimen. The color of fracture was: indigo blue at $350^{\circ} \mathrm{C}$, dark purple above $400^{\circ} \mathrm{C}$ without metallic luster. The necking phenomenon of the place where the specimen was damaged was increasingly evident.

3.2 Results of High-temperature Tensile Property Test and Analysis. It was noted that elastic modulus, yielding strength and ultimate strength showed a small rise tendency, and there was hardening phenomenon and the material had an obvious yielding phase at $25^{\circ} \mathrm{C}$ to $300^{\circ} \mathrm{C}$.

Table 1 Mechanical properties of the $Q 235$ galvanized sheet at elevated temperature

\begin{tabular}{ccccc}
\hline $\mathrm{T} /{ }^{\circ} \mathrm{C}$ & $\mathrm{E} /\left(10^{5} \mathrm{Mpa}\right)$ & $f_{y} / \mathrm{MPa}$ & $f_{u} / \mathrm{MPa}$ & $\delta \%$ \\
\hline 20 & 2.12 & 212.0 & 320.9 & 41.1 \\
150 & 2.25 & 200.9 & 331.3 & 33.2 \\
200 & 2.21 & 199.7 & 345.3 & 33.0 \\
250 & 1.99 & 194.8 & 338.7 & 32.3 \\
300 & 1.93 & 199.8 & 350.0 & 28.0 \\
350 & 1.89 & 197.4 & 331.0 & 40.0 \\
400 & 1.72 & 176.0 & 259.5 & 52.0 \\
450 & 1.57 & 170.3 & 221.0 & 54.0 \\
500 & 1.50 & - & 161.0 & 61.0 \\
550 & 1.34 & 121.8 & 131.0 & 64.0 \\
600 & 1.32 & 110.2 & 124.0 & 66.0 \\
700 & 1.16 & 47.8 & 60.0 & 68.0 \\
\hline
\end{tabular}

It was seen from the results listed in Table 1 that three mechanical indexes showed a declined tendency At $300^{\circ} \mathrm{C}$ to $700^{\circ} \mathrm{C}$, which got much rapider above $450^{\circ} \mathrm{C}$, which meant that the bearing capacity of the specimen had gradually lost and its stress-strain curve did not have an obvious yielding phase any more. As shown in Table 1 , at $25^{\circ} \mathrm{C} \sim 300^{\circ} \mathrm{C}$, the elongation percentage of the galvanized sheet showed a small declined tendency with temperature rise and the specimen tends to be brittle; At $300^{\circ} \mathrm{C} \sim 700^{\circ} \mathrm{C}$, the elongation percentage began to increase, which had increment of $68 \%$ at $700^{\circ} \mathrm{C}(1.6$ times as that of normal temperature), and the specimen got into the plastic flowing state. 
3.3. Results of High-temperature Creep Property Test. As shown in Figure 3, the 50-minute creep curves of Q235 galvanized sheet in three different stress levels were highly similar which included a period of initial creep at first and a period of steady creep at $200^{\circ} \mathrm{C}$. It is seen that the 50-minute creep strain was $680 \mu \varepsilon$ as the stress was $0.6 f_{u}$ at $200^{\circ} \mathrm{C}$, and the 50 -minute creep strain turned into $524 \mu \varepsilon$ whenever the stress was $0.2 f_{u}$. In the stress level of $0.4 f_{u}$, specimen got straight into the period of accelerated creep, and fractures in 50 minutes.

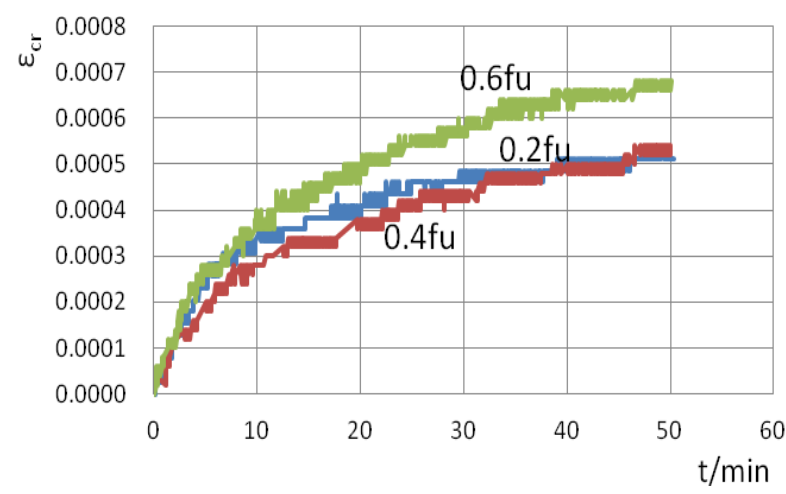

(a) Creep curve at $200^{\circ} \mathrm{C}$

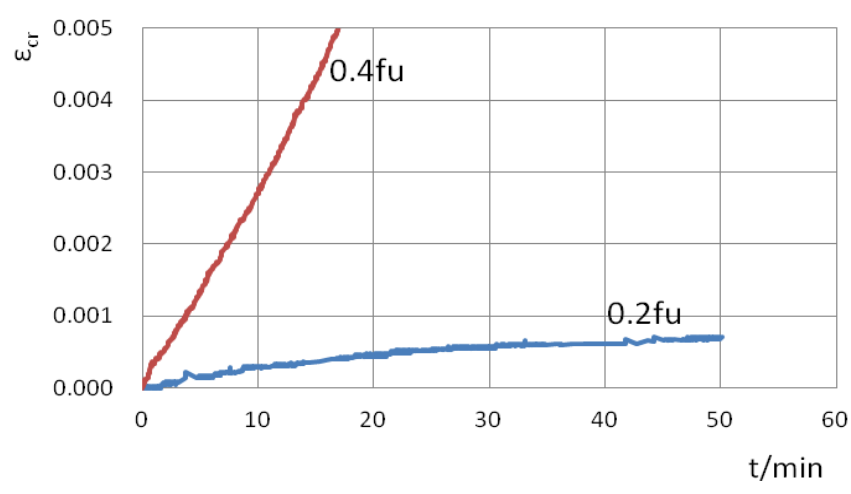

(b) Creep curve at $500^{\circ} \mathrm{C}$

Fig. 3 Creep curves at measured temperature points

\section{Conclusions}

Based on the results and analysis of experiments, the conclusions were reached as : (1) The surface feature of specimen after cooling didn't have the original luster and the surface appeared a little dark and the zinc coat nearly disappears at $500^{\circ} \mathrm{C}$ to $600^{\circ} \mathrm{C}$. The fracture was completely black and there was no metallic luster. Necking phenomenon of the place where the specimen was damaged was quite evident and the shrinking percentage of fracture was larger. (2) At $300^{\circ} \mathrm{C}$ to $700^{\circ} \mathrm{C}$, the mechanical indexes showed a declined tendency which got much rapider above $450^{\circ} \mathrm{C}$, which meant that the bearing capacity of the specimen had gradually lost.

\section{Acknowledgements}

This work was financially supported by the Applied Research Project of Public Welfare Technology of Zhejiang Province (2017C33013)

\section{References}

[1] H. M. Jiang, X.P. Chen and H. Wu: Forging and Manufacturing Technology Vol.3 (2005), p.65 (in Chineses).

[2] T. Ranawaka, M. Mahendran: Fire Safety Journal Vol. 44 (2009), p. 219.

[3] W. Chen, J. H. Ye : Journal of Constructional Steel Research Vol.73(2012), p. 1.

[4] N. D. Kankanamge, M. Mahendran: Thin-Walled Structures, Vol. 49(2011), p.26.

[5] Y. Huang, B. Young: Journal of Constructional Steel Research, Vol.92 (2014), 92, p.103.

[6] S. Yan, B. Young: Engineering Structures, Vol.35 (2012), p. 234. 